\title{
Observational Experiment and Predictability of High-Impact Weather
}

\author{
Dong-Eon Chang ${ }^{1}$, Dong-Kyou Lee ${ }^{2}$ and Seon Ki Park ${ }^{3}$ \\ ${ }^{1}$ Forecast Research Division, National Institute of Meteorological Research, Korea Meteorological Administration, Seoul, Korea \\ ${ }^{2}$ School of Earth and Environmental Sciences, Seoul National University, Seoul, Korea \\ ${ }^{3}$ Department of Environmental Sciences and Engineering, Severe Storm Research Center, and Center for Climate/Environment Change Prediction \\ Research, Ewha Womans University, Seoul, Korea
}

(c) The Korean Meteorological Society and Springer 2010

\begin{abstract}
Understanding the mechanism and predictability of highimpact weather phenomena, including heavy rainfall, strong windstorms and tropical cyclones, is one of the most challenging problems given that these events exert a considerable effect on the society, the economy, and the natural environment. Intensive observations, in addition to operational observation networks, are vital to enhancing our understanding of high-impact weather systems. The US National Research Council (NRC) noted that improved observing capabilities at the mesoscale are foremost among weather-related socioecomomic priorities including reduction of vulnerability in densely populated areas, and improvement in forecasts at the scale of flash floods and routinely
\end{abstract} disruptive local weather (NRC, 2010).

Many regional field observational programs have been conducted for better understanding of severe weather phenomena in the East Asia. A prime example is the Taiwan Area Mesoscale Experiment (TAMEX; Kuo and Chen, 1990), which focused on scientific issues of mesoscale circulations associated with the Mei-Yu front, the evolution of mesoscale convective systems (MCSs), and the effect of orography on MCSs. Narrowing down the focus to the key physical processes, such as the onset and evolution of the summer monsoon over Southeast Asia and southern China for improved monsoon prediction, an international field experiment entitled the South China Sea Monsoon Experiment (SCSMEX) was implemented in 1998 (Lau et al., 2000). As a national-level comprehensive observational program, the Korea Monsoon Experiment (KORMEX; Oh et al., 1997) was designed and implemented in collaboration with international field programs such as SCSMEX and GAME (GEWEX Asian Monsoon Experiment; WCRP, cited 2010).

Building on the success of these regional field campaigns and driven by the need to more precisely characterize high-impact weather systems over the Korean peninsula, the Korea Enhanced Observing Program (KEOP) was initiated in 2001 by the National Institute of Meteorological Research. The first phase (2001-2005) of KEOP focused on high spatial and temporal

Corresponding Author: Dong-Eon Chang, Forecast Research Division, National Institute of Meteorological Research, Korea Meteorological Administration, Seoul 156-720, Korea

E-mail : dechang@kma.go.kr density observations for frontal systems and typhoons around the Haenam supersite, which is located in the southwestern part of Korea. The program subsequently extended its observational scope to mountain and downstream meteorology and heavy rainfall in the central region (Kim and Park, 2008). The observational datasets from the KEOP field experiments are archived and available on the web, at http://probex.nimr.go.kr/obs. In 2008, the KEOP field experiment was conducted in association with an international field campaign, the Observing system Research and Predictability Experiment (THORPEX) Pacific Asian Regional Campaign (T-PARC). THORPEX was established in 2003 by World Meteorological Organization (WMO) to further enhance the accuracy and the social, economic, and environmental benefits of 1-day to 2-week high-impact weather forecasts (WMO, 2005). Potential benefits of THORPEX in Korea and East Asia are well emphasized in Park (2004). Main objectives of the T-PARC 2008 were to investigate tropical cyclone formation, intensification, recurvature, and extra-tropical transition. The campaign also included targeted observations to improve track forecasts. A total of four aircraft were operated for the combined T-PARC, Tropical Cyclone Structure Experiment (TCS-08), and DOTSTAR programs (Weissmann et al., 2010; Elsberry et al., 2009; Wu et al., 2005). This is a good example of establishing international synthetic observation network in the East Asia, as insisted by Park (2005).

In November 2009, a workshop on the "Observational Experiment and Predictability of High-Impact Weather" was held in Seoul. The workshop discussed a wide range of scientific topics, encompassing the structure of high-impact weather, data assimilation, and predictability study based on special observation experiments including KEOP. Most of the contributions to this special issue were inspired by those discussions, and cover such topics as observational characteristics of atmospheric water vapor retrieved from GPS and microwave radiometers, as well as inertial gravity waves revealed by radiosonde observation under the KEOP program. There are also articles dealing with data assimilation and uncertainty studies on typhoon cases from TPARC field experiments based on aircraft dropsonde observations. Furthermore, modeling studies on MCSs are included with a view to improving understanding of this phenomenon and forecast skill. Finally, outcomes of precipitation nowcasting using 
radar observations and related verification studies are presented.

Weather-related disasters result in significant loss of life and property in all parts of the world. In the United States, the 2005 Hurricane Katrina left in its wake nearly 1,500 direct weather fatalities and more than $\$ 100$ billion in property damage (NRC, 2010). The most disastrous weather year in Korea was 2002 due to Typhoon Rusa, which resulted in property damage of about $\$ 4.5$ billion and 184 casualties (NEMA, cited 2010). Better forecasts and warnings are critical for lowering these numbers. We hope that the research activities documented in this special issue contribute to the progress of the science and forecast skill regarding high-impact weather systems and a safer society for the public.

\section{REFERENCES}

Elsberry, R. L., W. Clune, G. Elliott, and P. Harr, 2009: Evaluations of global model early track and formation predictions during the combined TCS08 and T-PARC field experiment. Asia-Pacific J. Atmos. Sci., 45, 357-373.

Kim, H. H., and S. K. Park, 2008: Current status of intensive observing period and development direction. Atmosphere, 18, 147-158. (in Korean with English abstract)

Kuo, Y.-H., and G. Chen, 1990: The Taiwan Area Mesoscale Experiment (TAMEX): An overview. Bull. Amer. Meteor. Soc., 71, 488-503.

Lau, K. M., and Coauthors, 2000: A report of the field operations and early results of the South China Sea Monsoon Experiment (SCSMEX). Bull. Amer. Meteor. Soc., 81, 1261-1270.

National Emergency Management Agency, cited 2010: Disaster report. [Available online at http://eng.nema.go.kr.]

National Research Council, 2010: When Weather Matters: Science and Service to Meet Critical Societal Needs. The National Academic Press, $146 \mathrm{pp}$.

Oh, J.-H., W.-T. Kwon, and S.-B. Ryoo, 1997: Review of the researches on Changma and future observational study (KORMEX). Adv. Atmos. Sci., 14, 207-222.

Park, S. K., 2004: The Observing System Research and Predictability Experiment (THORPEX) and potential benefits for Korea and the East Asia. Atmosphere, 14, 41-54.

2005: Observation programs: Current status and future visions. Atmosphere, 15, 141-148. (in Korean with English abstract)

Weissmann, M., F. Harnisch, C.-C. Wu, P.-H. Lin, Y. Ohta, K. Yamashita, Y.-H. Kim, E.-H. Jeon, T. Nakazawa, and S. Aberson, 2010: The influence of dropsondes on typhoon track and mid-latitude forecasts. Mon. Wea. Rev., in press.

World Climate Research Program, cited 2010: GEWEX Asian Monsoon Experiment (GAME). [Available online at http://www.gewex.org/game. html.]

World Meteorological Organization, 2005: THORPEX International Research Implementation Plan. WMO/TD-No. 1258, 95 pp.

Wu, C. C., and Coauthors, 2005: Dropsonde Observations for Typhoon Surveillance near the Taiwan Region (DOTSTAR): An overview. Bull. Amer. Meteor. Soc., 86, 787-790. 